\title{
Investigation of the effect of different materials on convective heat transfer
}

\author{
A. A. Ibrahim¹, P. L. Chong², V. S. Rajasekharan ${ }^{3}$, M. M. Ali3 , O. S. Zaroog' ${ }^{4}$ and A. N. Oumer ${ }^{5}$ \\ 1 Higher Colleges of Technology, Faculty of Engineering, Technology and Science, Mechanical Engineering Division, Nahyan the $1^{\text {st }}$ Street, \\ Al Ain Abu Dhabi, UAE. \\ 2 Teesside University, School of Computing, Engineering \& Digital Technologies, Stephenson Street, Middlesbrough TS1 3BX, UK. \\ Phone: +4401642384420 \\ ${ }^{3}$ INTI International University, Persiaran Perdana BBN, 71800 Nilai, Negeri Sembilan, Malaysia. \\ ${ }^{4}$ Sohar University, Mechanical and Mechatronic Engineering, Faculty of Engineering, Sohar, Sultanate of Oman. \\ 5 Universiti Malaysia Pahang, Faculty of Mechanical Engineering, 26600 Pekan, Pahang, Malaysia.
}

ABSTRACT - Conventionally, the study of convection heat transfer merely focuses on the behavior of air flow without considering the conductive effect of the horizontal flat plate. However, it is expected that the conductive effect of the horizontal plate somewhat affects the air flow temperature across the flat plate. Therefore, it is motivated to study the variation of air flow temperature across different materials of flat plate in various time frame. The materials used in this study are aluminium, stainless steel and cast iron. Infrared camera and FloEFD simulation software are used to measure the upper surface temperature of the flat plate. For forced convection, the study is carried out within the range of $10^{3} \leq R e \leq 10^{4}$ and within the range of $1 \times 10^{7} \leq R a<2.2$ $\times 10^{7}$ for natural convection. Flow velocity of $2.3 \mathrm{~m} / \mathrm{s}, 4.1 \mathrm{~m} / \mathrm{s}$ and $5.2 \mathrm{~m} / \mathrm{s}$ are used for the forced convection. The results showed that aluminium plate cools down faster than the other two metal plates used in all scenarios. Stainless steel's temperature goes down faster compared to cast iron. These results were supported by the fact that aluminium has higher heat transfer rate of other metals. For forced convection, the discrepancies of temperatures between experimental and simulation studies are below $10 \%$, which demonstrates that the results are reasonably acceptable. For natural convection, even though the discrepancies between simulation and experimental results on temperature variations are relatively large, the temperatures varied in similar pattern. This indicates that the results are reliable.
ARTICLE HISTORY

Revised: $13^{\text {th }}$ Dec 2019

Accepted: $19^{\text {th }}$ Dec 2019

\section{KEYWORDS}

Heat transfer;

natural convection;

forced convection;

experimental;

simulation;

rate of heat transfer;

thermal conductivity..

\section{INTRODUCTION}

A study of conjugate heat transfer of natural and forced convection through horizontal thin plates has been under investigation since year of 1960. This area of study covers broad spectrum of engineering aspects, such as thermal effect of solar receiver [1], thermal performance of solar heater [2], convective heat transfer of impinging jets [3], cooling of mixed convection jet impingement [4], heat transfer and flow characteristics of plate heat exchanger [5], thermal influence of geometric design of plate fin [6] and many others.

Classen [7] performs theoretical investigation on laminar boundary layer of a heated horizontal surface, which demonstrates that the boundary layer is different from the inclined or vertical surface due to buoyancy force acting upon the boundary layer. Measurement of boundary layer thickness can be achieved by using Rapid Compression Machine (RCM) [8], but this does not reflect the factor affecting by the plate material. The effect of natural convection has been studied experimentally on different geometries of flat plate, which demonstrates the geometry has no effect to the local heat transfer rate in the turbulent region if the plate is infinitely large [9]. Similar experimental study on natural convection has been conducted for copper and steel plates, which concludes that there is no significant dependence of the Nusselt number $(\mathrm{Nu})$ with respect to aspect ratio of the plate [10]. Schaub et al. [11] perform experimental investigation of unsteady natural convection at a vertical flat plate. Subsequently, the experimental results have been used to develop an analytical model that can predict unsteady natural convection at vertical flat plate [12]. Akdaq et al. [13] implement artificial neural network to predict the heat transfer of flat plate under pulsating jet, the more advanced numerical method produces more accurate results. Kröger [14] deduced the correlation of convection heat transfer coefficients by taking into account the radiative effect, which is well aligned to the experimental measurement. Jang et al. [15] investigates the flat plate pulsating heat pipes with various asymmetric ratios and aspect ratios in the channels, the optimum asymmetric ratio and aspect ratio are determined. Guoneng et al. [16] conducted experimental study on convective heat transfer from a flat plate impinged by a row of laminar air jets, from which a new Nu correlation is developed. Horibe et al. [17] experimentally investigated the relationship between heat transfer and flow behaviour in an enclosure containing parallel heaters, it has been found that the flow tends to move along the heated surface and exhibits vortex motion. Madanan et al. [18] studied the high Rayleigh number $(R a)$ thermal convection of gas flow in tilted rectangular enclosure. Boukhattem 
et al. [19] conducted similar study through 2-D numerical modelling, it has been found that the increase of Rayleigh number $(R a)$ leads to increase the convective effect relative to the conductive effect of the flow. Liu et al. [20] found that the widths of heated plate significantly affect the heat transfer coefficient, where the heat transfer coefficient of narrow heated plate are much higher than those of wide ones under the same velocity and pressure. Elsberbiny et al. [21] conducted numerical study on the heat transfer and flow characteristics for natural convection from a horizontal isothermal square cylinder, a new correlation between $\mathrm{Ra}$ and $\mathrm{Nu}$ was developed. Jamalabadi [22] used infrared camera to investigate the most significant parameters that governed the surface temperature of thin plate under convection heat transfer. Whereas, Ceglia and Discetti [23] investigated the thermal boundary layer across the horizontal plate by using infrared thermography. All the above mentioned literatures provide some insights on correlation of flow patterns to convective heat transfer coefficient. However, the findings do not reveal how the material properties affect the convective effect.

Therefore, the aim of this paper is to investigate the thermal effect of horizontal thin plates towards the surrounding air in term of different materials such as aluminum, stainless steel and cast iron. Throughout the remaining of the sections, the experimental and numerical methods are described. In addition, the mathematical model for natural and force convections are detailed. Subsequently, the simulation and experimental results are compared, critical results analysis are demonstrated. Finally, the overall achievements are concluded and the key findings are highlighted.

\section{METHODOLOGY}

\section{Solid Model and Material Properties}

Aluminum, stainless steel and cast iron are commonly used in heat exchanger [24,25]. The heat transfer properties of those materials are tabulated in Table 1 . For this research, $100 \mathrm{~mm}$ by $100 \mathrm{~mm}$ square plates of each material are used as shown in Figure 1. The thickness of all the plates are $5 \mathrm{~mm}$.

Table 1. Densities and specific heats used in simulation.

\begin{tabular}{cccc}
\hline Material & Density $\left(\mathrm{kg} / \mathrm{m}^{3}\right)$ & $\begin{array}{c}\text { Specific Heat } \\
\left(\mathrm{J} / \mathrm{Kg}^{\circ} \mathrm{C}\right)\end{array}$ & $\begin{array}{c}\text { Thermal Conductivity } \\
\left(\mathrm{W} / \mathrm{m}^{\circ} \mathrm{C}\right)\end{array}$ \\
\hline Aluminium & 2712 & 904 & 235 \\
Stainless Steel & 7480 & 490 & 29.42 \\
Cast Iron & 6800 & 460 & 62.316 \\
\hline
\end{tabular}

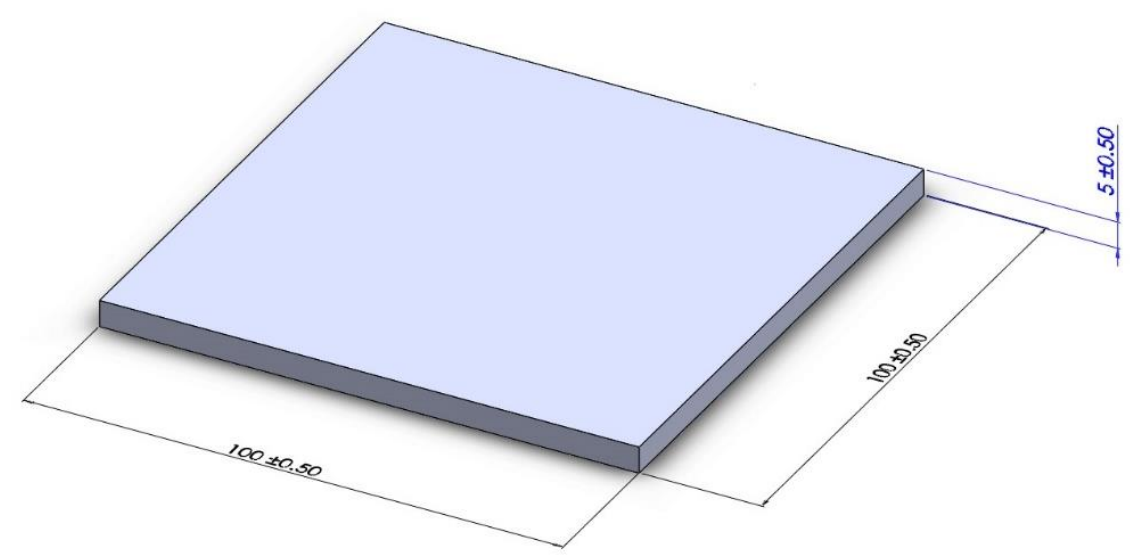

Figure 1. Dimension of thin plate using SolidWorks 3D CAD model.

\section{Experimental Rig}

The main idea is to individually heat up three plates of different materials as mentioned in previous section. The first step is to place the plate into the muffle furnace until it is heated up to $200^{\circ} \mathrm{C}$. The temperature distribution is visualised through infrared camera after the materials are removed from the furnace and kept in controlled environment. The camera was located at $400 \mathrm{~mm}$ above the heated plate for best visualization as shown in Figure 2. The infrared camera operates in parallel with thermographic software for real time data acquisition. Some key parameter values as shown in Table 2 are entered into the infrared camera. 
For the case of forced convection, the flow velocity of $2.3 \mathrm{~m} / \mathrm{s}, 4.1 \mathrm{~m} / \mathrm{s}$, and $5.2 \mathrm{~m} / \mathrm{s}$ are applied. Then, the temperature reading is taken every $60 \mathrm{~s}$ until $360 \mathrm{~s}$ by using infrared camera. For the case of natural convection, the temperature reading is taken in the same time intervals without applying flow velocity.

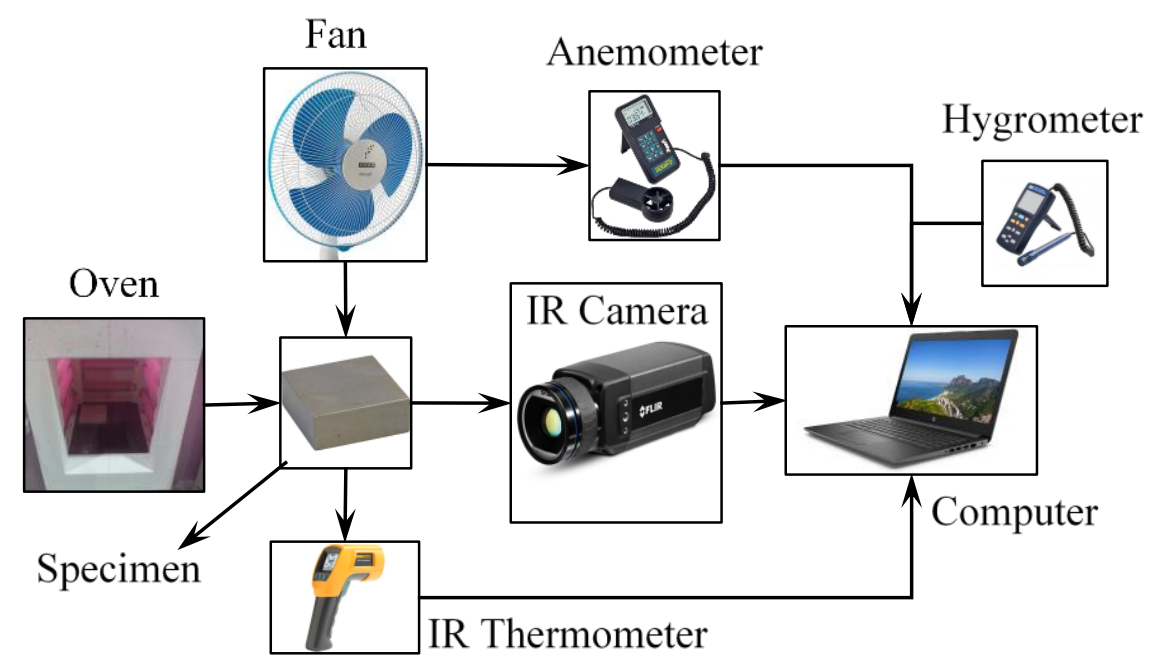

Figure 2. Experimental setup.

Table 2. FLIR infrared camera parameters.

\begin{tabular}{ll}
\hline Parameters & \\
\hline Image Object Parameters & \\
Emissivity & 0.95 \\
Refl. Apparent Temp.: & $0.0^{\circ} \mathrm{C}$ \\
Atmosphere Parameters & \\
Atmospheric temperature (-273.2- 5476.8) & $30.0^{\circ} \mathrm{C}$ \\
Relative humidity $(0.00-1.00)$ & 0.5 \\
Distance (0.0 - 50000.0) & $0.04 \mathrm{~m}$ \\
External Optics & \\
Temperature & $20.0^{\circ} \mathrm{C}$ \\
Transmission: $(0.00-1.00)$ & 1 \\
\hline
\end{tabular}

\section{Simulation}

Initially, the flat plate model (Figure 1) is imported to the FloEFD software and an enclosure is set up to specified the region of air flow for the preparation of CFD simulation. FloEFD employs Navier-Stokes equations to describe both laminar and turbulent flows.

Total of 12 simulations conducted during the research, three simulations were for natural convection and nine simulations were for forced convection. For each simulation, separate project created with similar characteristics as the corresponding experimental procedure. The air flow is set as laminar and the humidity level is set as $50 \%$, which coincides with the experimental environment. Properties of the materials defined according to the material specifications given in Table 1. Default wall conditions of the software kept and the initial conditions set accordingly. As the thin plate is exposed to the atmosphere, the air pressure is set as $100 \mathrm{kPa}$ and the surrounding air temperature is $303 \mathrm{~K}$. The temperature of the flat plate is set at $473 \mathrm{~K}$ at the initial stage $t=0$.

In terms of mesh size, the minimum size is set as $1 \mathrm{~mm}$, which provides sufficiently dense meshing with 464,192 nodes and 315,641 elements for the thickness of the flat plate of $5 \mathrm{~mm}$. The mesh quality was checked in the simulation and gives $99.9 \%$ for percentage of elements with Aspect Ratio <3, which indicate that the mesh size is appropriate.

For natural convection, the air flow regions within the enclosure is set as environmental pressure openings, which reflects the thin plate fully exposing to the open air environment. In the case of natural convection, flow velocity is negligible. For forced convection, an inlet wall with the inlet flow with various velocities are set according to the experimental conditions. After setting the boundary conditions, the simulation was run with surface temperature as the goal of the project. After the analysis completed, the surface plots for the temperature observed, along with the change in the temperature of the plates with time. These results compared with the results from the experimental procedures. 


\section{Experimental Calculation}

The aim of the mathematical procedures is to determine the convection heat transfer coefficient $h$, which allows the rate of convective heat transfer $\dot{Q}$ to be calculated. In doing so, the first step is to calculate the film temperature $T_{f}$ as follow:

$$
T_{f}=\frac{\left(T_{s}+T_{\infty}\right)}{2}
$$

where, $T_{s}$ is surface temperature and $T_{\infty}$ is surrounding temperature. Based on $T_{f}$, the kinematic viscosity, $\vartheta\left(\mathrm{m}^{2} / \mathrm{s}\right)$ and Prandtl number, $\operatorname{Pr}$ can be found. For natural convection, the Rayleigh number needs to be calculated as follow:

$$
R a=\mathrm{Gr} . \operatorname{Pr}=\frac{\mathrm{g} \beta\left(T_{s}-T_{\infty}\right) L_{c}^{3}}{\vartheta^{2}} \operatorname{Pr}
$$

where $g$ is constant gravity, $G r$ is Grashof number, $\beta$ is expansion coefficient expressed by $\beta=1 / T_{f}$. For forced convection, Reynolds needs be calculated as follow:

$$
R e=\frac{\mathrm{U} L_{c}}{\vartheta}
$$

where, $U$ is flow velocity. For the case of natural convection, the Nusselt number is given by:

$$
N u=\frac{\mathrm{h} L_{c}}{\mathrm{k}}=f(R a, \mathrm{Pr})
$$

where, $f(R a, \operatorname{Pr})$ is experimental correlation function that can be adapted from [26]. For the case of forced convection, the Nusselt number is given by:

$$
N u=\frac{\mathrm{h} L_{c}}{\mathrm{k}}=g(R e, \operatorname{Pr})
$$

where, $g(R e, \mathrm{Pr})$ is experimental correlation function that can be adapted from [27]. Once the convective heat transfer coefficient $h$ is obtained from either (4) or (5), the rate of heat transfer can be determined by:

$$
\dot{Q}=h A_{s}\left(T_{s}-T_{\infty}\right)
$$

\section{RESULTS AND DISCUSSION}

\section{Surface Temperature at Natural Convection}

To measure the surface temperature, high-resolution science grade infrared camera is used. As an example, the image contour of aluminium at 0 second is illustrated in Figure 3. Initially $(t=0 \mathrm{~s})$, the temperature is set to $200^{\circ} \mathrm{C}$ with measured uncertainty of $\pm 1.3^{\circ} \mathrm{C}$ for natural convection experiment. Based on the infrared camera, the final temperature (at $t=300 \mathrm{~s}$ ) for aluminum, stainless steel and cast iron are $108^{\circ} \mathrm{C}, 124.9^{\circ} \mathrm{C}$ and $132.9^{\circ} \mathrm{C}$, respectively.

For the stainless steel, the final temperature at 300 seconds is $157^{\circ} \mathrm{C}$. For the cast iron, the final temperature at $300 \mathrm{~s}$ is $160^{\circ} \mathrm{C}$. By using FloEFD simulation, at $t=300 \mathrm{~s}$, final temperature of aluminum is $153^{\circ} \mathrm{C}$ as shown in Figure 4 . Figure 5 shows the experimental and computational results of surface temperature change of horizontal thin plates under natural convection. The main concern is to investigate the effect of natural convection towards different materials such as aluminum, stainless steel and cast iron, where the initial surface temperatures are set to be $200^{\circ} \mathrm{C}$. The trend of the graph shows, the surface temperature of all types of materials decreases over time non-linearly, since there is no continuous heat addition source after the materials are heated up to $200^{\circ} \mathrm{C}$. Hence, it is transient state heat transfer characteristics with temperature changing over time. 


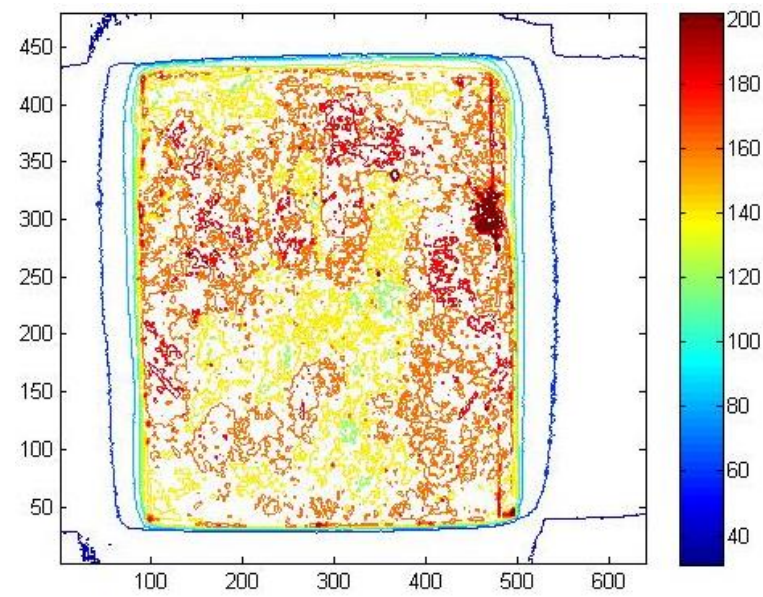

Figure 3. Surface temperature under natural convection at 0 seconds (initial temperature) by infrared camera.
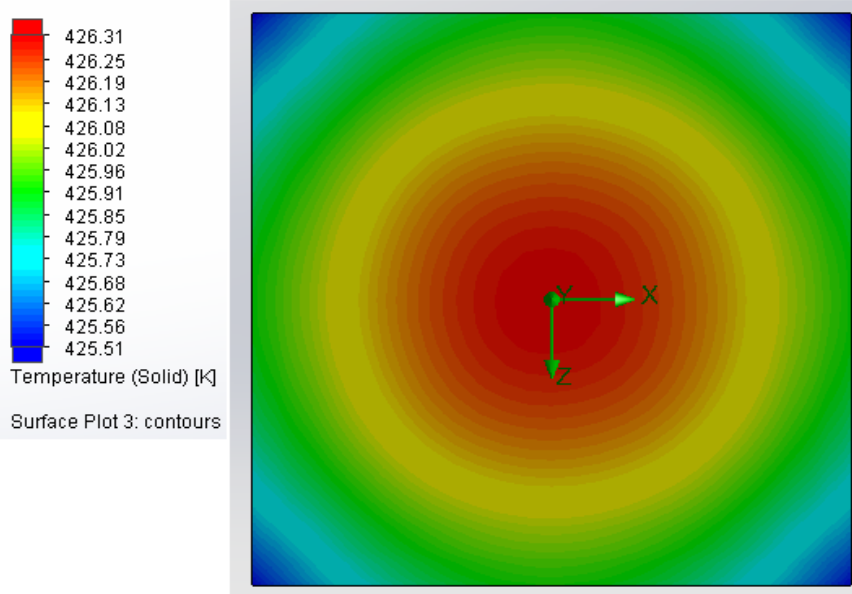

Figure 4. Surface temperature under natural convection at 300 seconds by floEFD simulation.

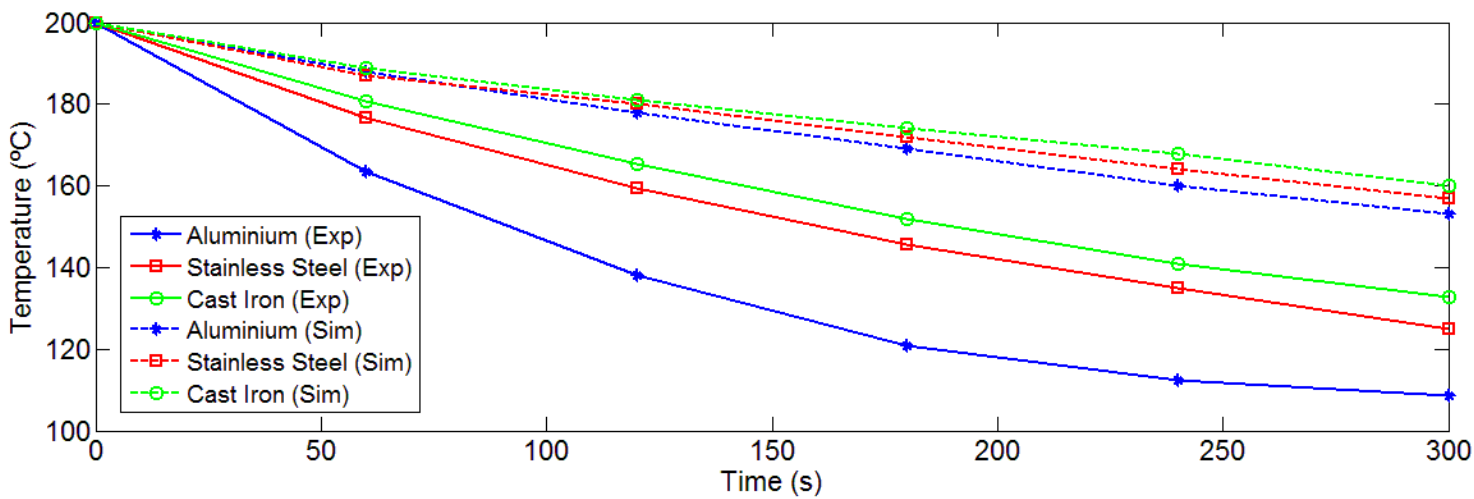

Figure 5. Experimental and simulation of surface temperature by natural convection.

Considering the surface temperatures of cast iron at $60 \mathrm{~s}$, the computational surface temperature drops to $190^{\circ} \mathrm{C}$, whereas the experimental surface temperature drops to $182^{\circ} \mathrm{C}$. The discrepancy between computational and theoretical surface temperatures is $4.4 \%$, which is reasonably close. However, when considering the surface temperature of cast iron at $300 \mathrm{~s}$, the computational and experimental surface temperatures are $170^{\circ} \mathrm{C}$ and $142^{\circ} \mathrm{C}$, respectively, and the discrepancy is $19.71 \%$. The high discrepancy of $19.71 \%$ is due to the fact that cumulative effect of variations of humidity, flow velocity and buoyancy forces cannot be captured in simulation result. In addition, the cumulative effect causes that the temperature drop of experimental surface temperature is higher than that of computational surface temperature. 
Although the discrepancies between computational and experimental surface temperatures are rather high after $100 \mathrm{~s}$, the trends of surface temperature drop are somewhat agreeable. This indicates that the experimental surface temperatures are reliable. Similarly, the computational and experimental surface temperatures for both aluminum and stainless steel have agreeable trends. This demonstrates that the experimental surface temperatures for both aluminum and stainless steel are consistently reliable as of the cast iron.

Comparing the experimental surface temperatures drop among aluminum, stainless steel and cast iron, aluminum has the highest temperature drop (from $200^{\circ} \mathrm{C}$ to $120^{\circ} \mathrm{C}$ ), follow by stainless steel (from $200^{\circ} \mathrm{C}$ to $135^{\circ} \mathrm{C}$ ) and then cast iron (from $200^{\circ} \mathrm{C}$ to $142^{\circ} \mathrm{C}$ ). This could be due to the highest thermal conductivity of aluminium leads to the highest heat dissipation.

\section{Surface Temperature at Forced Convection}

The surface temperature of aluminum, stainless steel and cast iron for different flow velocity at 0 seconds to 300 seconds of simulation and experiment results are shown in Figures 8,9 and 10. The flow velocity is varied to $2.3 \mathrm{~m} / \mathrm{s}, 4.1$ $\mathrm{m} / \mathrm{s}$ and $5.2 \mathrm{~m} / \mathrm{s}$ and initial surface temperature is set to $200^{\circ} \mathrm{C}$ with measured uncertainty of $\pm 0.3^{\circ} \mathrm{C}, \pm 1.2^{\circ} \mathrm{C}$ and $\pm 2.2^{\circ} \mathrm{C}$, respectively.

For flow velocity of $2.3 \mathrm{~m} / \mathrm{s}$, the result shows that the temperature of aluminum, stainless steel and cast iron dropped to $86.4^{\circ} \mathrm{C}, 91.0^{\circ} \mathrm{C}$ and $96.7^{\circ} \mathrm{C}$ respectively. At this speed, discrepancies of resulting surface temperatures generated from simulation and experiment shows that aluminum has $8.1 \%$, stainless steel is $9 \%$ and cast iron is $7.9 \%$. At flow velocity of $4.1 \mathrm{~m} / \mathrm{s}$, aluminum has $1 \%$, stainless steel has $5.8 \%$ and cast iron has $7.2 \%$. At flow velocity of $5.2 \mathrm{~m} / \mathrm{s}$, aluminum has $3.9 \%$, stainless steel has $9 \%$ and cast iron has $9.7 \%$. The results show the surface temperature decreases as the time increases. The decrease in surface temperature is due to the fact that heat source is not continuously providing heat to the plates when the reading is taken. Based on the results, it can be seen that aluminum has the highest temperature drop compared to the other two metals, which could be due to the highest thermal conductivity of the aluminum. The higher flow velocity shows higher surface temperature drop. Similar results have been reported in [28], which demonstrates that the temperature drops are increased when increasing the flow velocity.

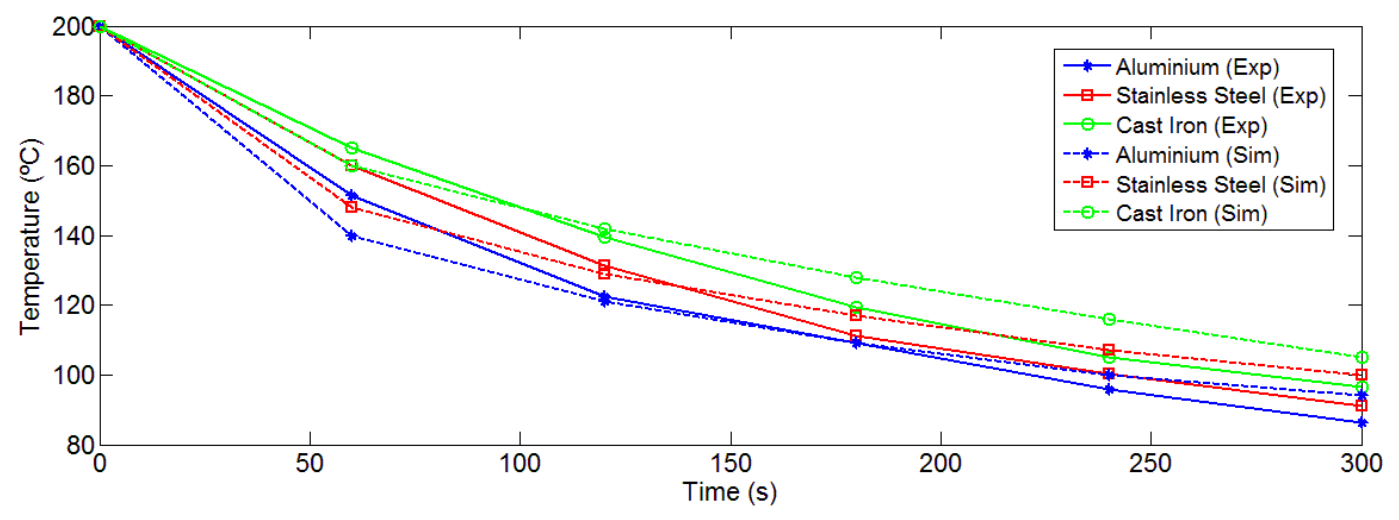

Figure 8. Surface temperature variation at flow velocity of $2.3 \mathrm{~m} / \mathrm{s}$.

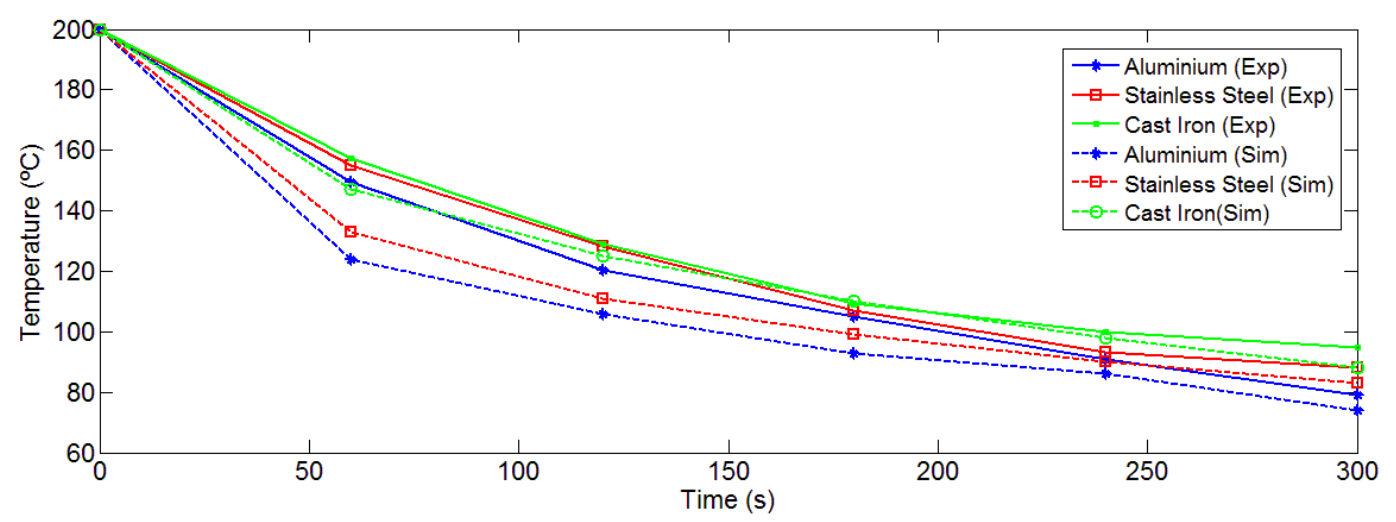

Figure 9. Surface temperature variation at flow velocity of $4.1 \mathrm{~m} / \mathrm{s}$. 


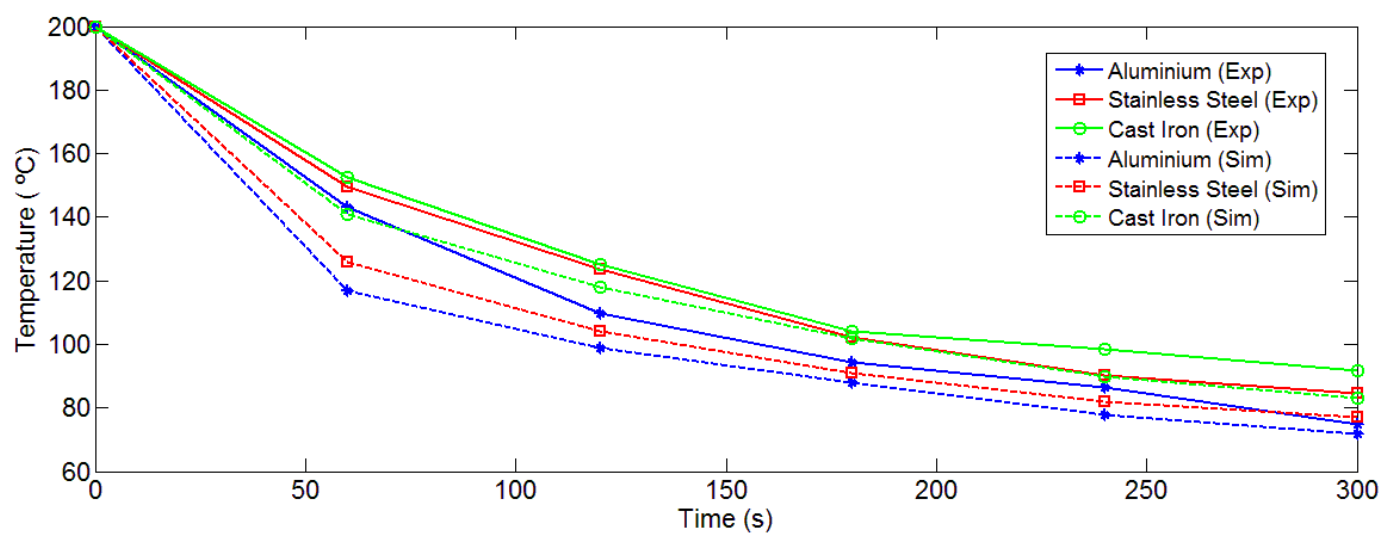

Figure 10. Surface temperature variation at flow velocity of $5.2 \mathrm{~m} / \mathrm{s}$.

\section{Rayleigh and Nusselt Number for Natural Convection}

In Figure 11, all plotted lines for experimental and simulation are rising up in linear trend. Since the initial temperature is $200^{\circ} \mathrm{C}$, the Rayleigh number and Nusselt number of all three materials for experimental and simulation is the same, which is $1.69 \times 10^{7}$ and 38.39 , respectively. In the experimental results, aluminum has the highest Nusselt $\left(2.04 \times 10^{7}\right)$ and Rayleigh numbers (40.99) at 300 seconds among the three materials. However, stainless steel has higher Nusselt $\left(2.03 \times 10^{7}\right)$ and Rayleigh number (40.92) compared to cast iron, which is $2.01 \times 10^{7}$ and 40.78 , respectively. In simulation results, aluminum has Rayleigh and Nusselt number of $1.90 \times 10^{7}$ and 40.03 , stainless steel has $1.89 \times 10^{7}$ and 39.96 and cast iron has $1.88 \times 10^{7}$ and 39.89 at 300 second, respectively.

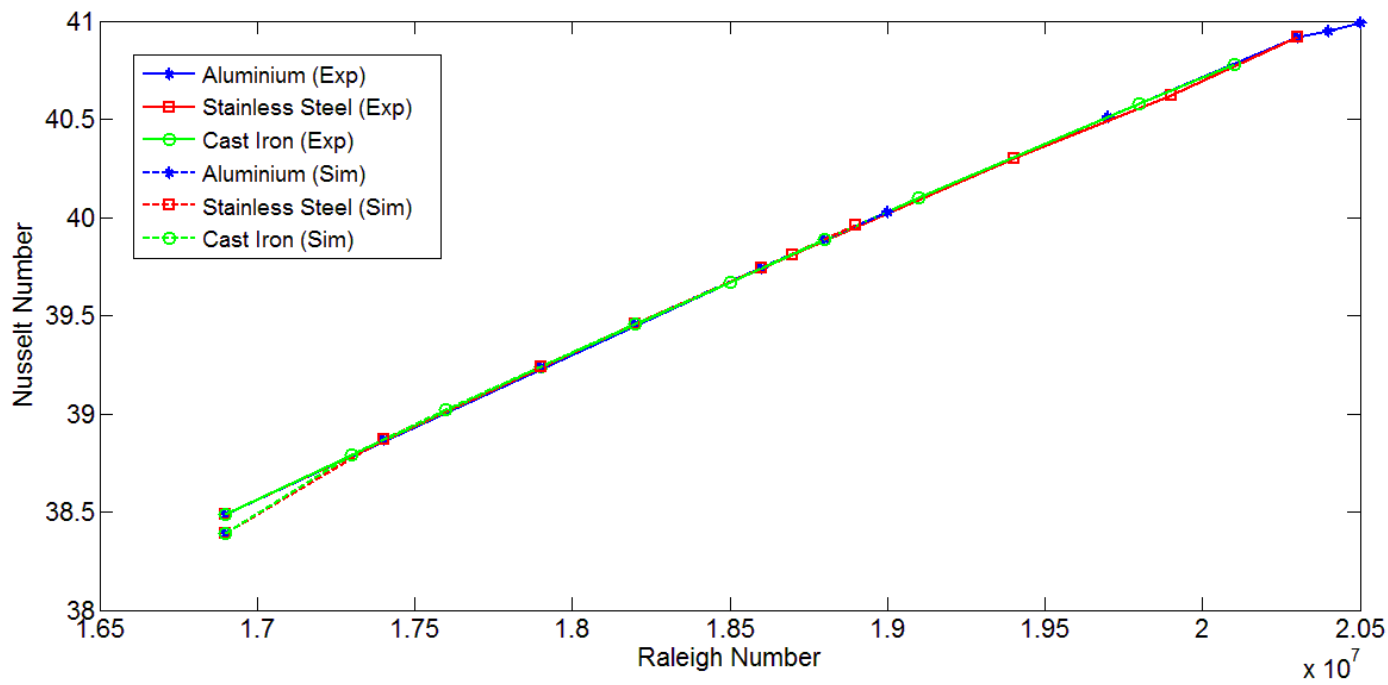

Figure 11. Rayleigh number against Nusselt number for natural convection.

\section{Reynolds and Nusselt Number for Forced Convection}

Figures 12, 13 and 14 show the variation of Nusselt number with respect to Reynolds number for the case of forced convection in both experimental and simulation studies. At flow velocity of $2.3 \mathrm{~m} / \mathrm{s}$, the Nusselt and Reynolds numbers at initial temperature $\left(200^{\circ} \mathrm{C}\right)$ are the same for all three materials, which are 57.14 and $0.93 \times 10^{4}$. The same constant initial temperature also applied for simulation. Similar to the case of natural convection as mentioned above, the variation of Nusselt Number to Reynolds Number is nearly coincides in both simulation and experimental studies at different flow velocitys as shown in Figures 12, 13 and 14. This can justify that the experimental and simulation results are reliable since both Nusselt and Reynolds numbers are purely related to the flow behaviour and has no relation to the conductivity of the material piece. However, there is a noticeable discrepancy of cast iron at the Reynolds number of $1.95 \times 10^{4}$ as shown in Figure 13, it could be due to the flow is still developing and the simulation hasn't fully captured the flow properties. 


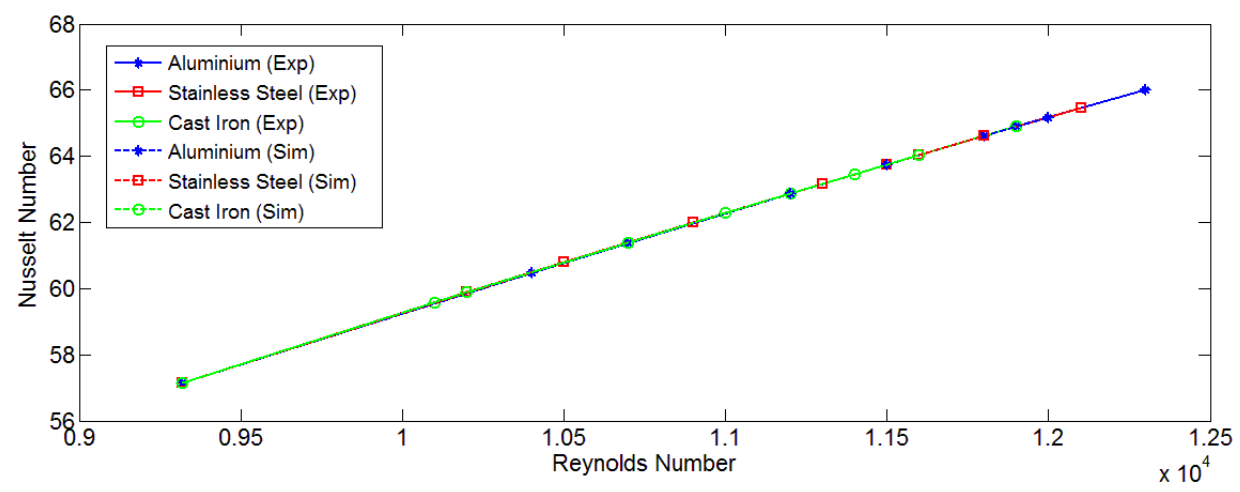

Figure 12. Reynolds number against Nusselt number at flow velocity $2.3 \mathrm{~m} / \mathrm{s}$.

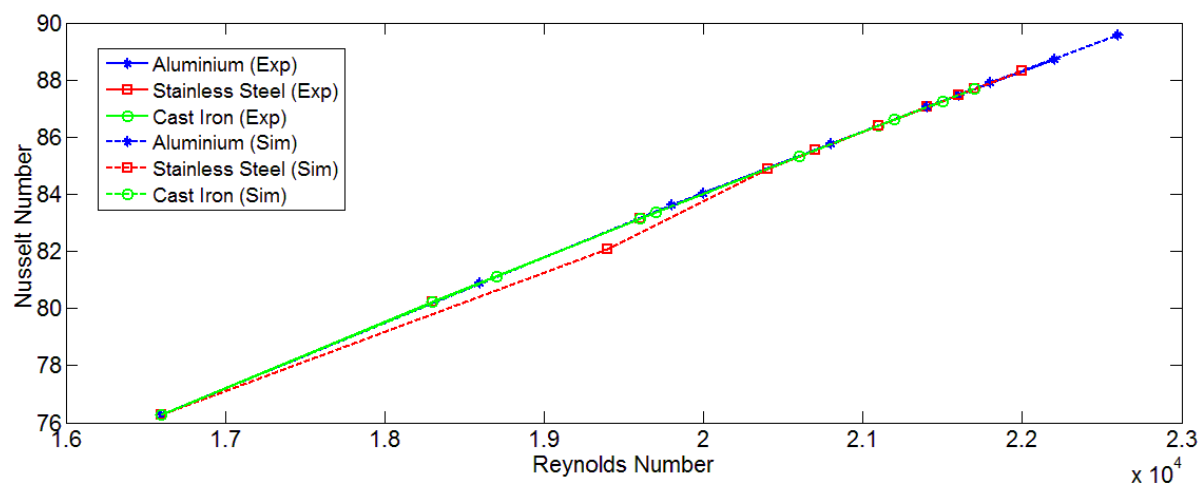

Figure 13. Reynolds number against Nusselt number at flow velocity $4.1 \mathrm{~m} / \mathrm{s}$.

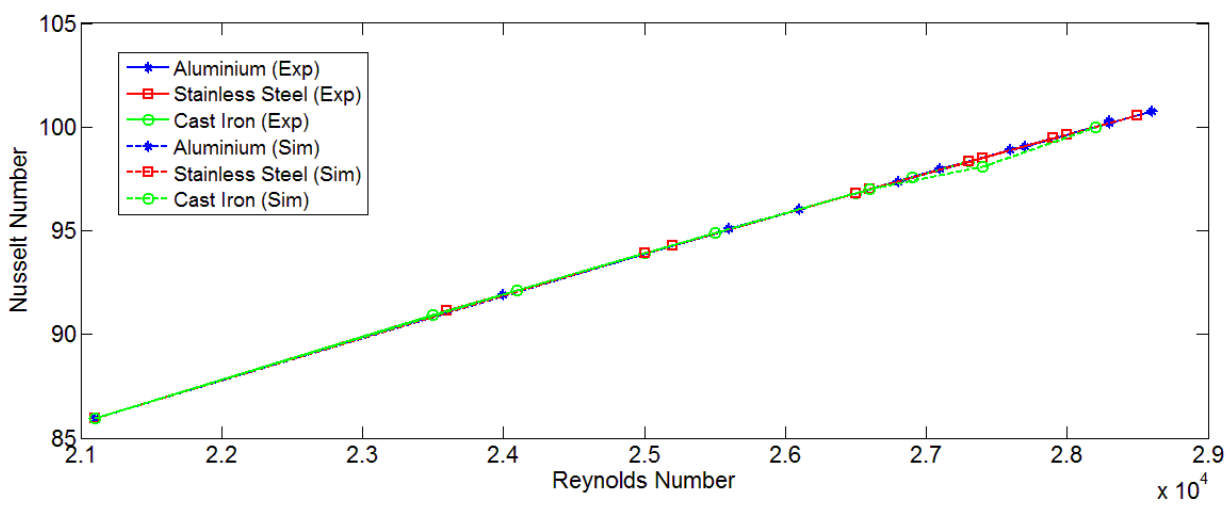

Figure 14. Reynolds number against Nusselt number at flow velocity $5.2 \mathrm{~m} / \mathrm{s}$.

\section{CONCLUSIONS}

The aim was to study some of the main factors affecting the heat transfer from thin metal plates. During the research, cooling of metal plates under natural and forced convection was simulated. Both the experimental and simulation studies are consistent, which demonstrates that the results are reliable. Throughout the studies, it has been found that aluminum thin plate has the highest temperature drop, followed by stainless steel then cast iron. This indicates the aluminum exhibits the most significant convective effect to the surrounding air, followed by stainless steel then cast iron.

All the results from the simulations and the experiments follow the similar pattern. For forced convection, the discrepancies between experimental and simulation results are below $10 \%$, which demonstrates that the results are reasonably accurate. For natural convection, the discrepancies between experimental and simulation results increased with respect to time, and the maximum discrepancy is up to $35 \%$. This is due to minor surrounding air flow causes disturbance of pure natural convection. In future research, it could be worthwhile to study how plastic material affects the convection heat transfer of the surrounding air. 


\section{ACKNOWLEDGEMENTS}

The authors would like to thank to the INTI International University for laboratory facilities and technical support.

\section{REFERENCES}

[1] S. Serra, A. Toutant, and F. Bataille, "Thermal large eddy simulation in a very simplified geometry of a solar receiver," Heat Transf. Eng., vol. 33, no. 6, pp. 505-524, Apr. 2012, doi: 10.1080/01457632.2012.624856.

[2] M. S. Manjunath, R. Venkatesh, and N. Madhwesh, "Thermal performance enhancement of flat plate solar air heater using transverse U-shaped turbulator - A numerical study,” J. Mech. Eng. Sci., vol. 13, no. 3, pp. 5562-5587, 2019, doi: 10.15282/jmes.13.3.2019.22.0448.

[3] G. Cafiero, G. Castrillo, C. S. Greco, and T. Astarita, "Effect of the grid geometry on the convective heat transfer of impinging jets," Int. J. Heat Mass Transf., vol. 104, pp. 39-50, 2017, doi: 10.1016/j.ijheatmasstransfer.2016.08.003.

[4] N. H. Saeid, B. S. Busahmin, and A. A. Khalid, "Mixed convection jet impingement cooling of a moving plate," J. Mech. Eng. Sci., vol. 13, no. 3, pp. 5528-5541, 2019, doi: 10.15282/jmes.13.3.2019.20.0446.

[5] N. B. Chien, O. Jong-Taek, H. Asano, and Y. Tomiyama, "Investigation of experiment and simulation of a plate heat exchanger," Energy Procedia, vol. 158, pp. 5635-5640, 2019, doi: 10.1016/j.egypro.2019.01.575.

[6] M. I. N. Ma'Arof, G. T. Chala, H. Husain, and M. S. S. Mohamed, "Influence of fins designs, geometries and conditions on the performance of a plate-fin heat exchanger-experimental perspective," J. Mech. Eng. Sci., vol. 13, no. 1, pp. 4368-4379, 2019, doi: 10.15282/jmes.13.1.2019.02.0372_rfseq1.

[7] L. Claassen, "Combined Free and Forced Convection From Horizontal Slowly Rotating Discs," University of British Columbia, 2019.

[8] M. Al-Sadoon and O. Samimi-Abianeh, "Gas temperature and boundary layer thickness measurements of an inert mixture using filtered broadband natural species emission (Part I)," J. Quant. Spectrosc. Radiat. Transf., vol. 241, p. 106749, 2020 , doi: 10.1016/j.jqsrt.2019.106749.

[9] M. Al-Arabi and M. K. El-Riedy, "Natural convection heat transfer from isothermal horizontal plates of different shapes," Int. J. Heat Mass Transf., vol. 19, no. 12, pp. 1399-1404, 1976, doi: 10.1016/0017-9310(76)90069-7.

[10] I. Martorell, J. Herrero, and F. X. Grau, "Natural convection from narrow horizontal plates at moderate Rayleigh numbers," Int. J. Heat Mass Transf., vol. 46, no. 13, pp. 2389-2402, 2003, doi: 10.1016/S0017-9310(03)00010-3.

[11] M. Schaub, M. Kriegel, and S. Brandt, "Experimental investigation of heat transfer by unsteady natural convection at a vertical flat plate,” Int. J. Heat Mass Transf., vol. 136, pp. 1186-1198, 2019, doi: 10.1016/j.ijheatmasstransfer.2019.03.089.

[12] M. Schaub, M. Kriegel, and S. Brandt, "Analytical prediction of heat transfer by unsteady natural convection at vertical flat plates in air," Int. J. Heat Mass Transf., vol. 144, pp. 1186-1198, 2019, doi: 10.1016/j.ijheatmasstransfer.2019.118665.

[13] U. Akdag, M. A. Komur, and S. Akcay, "Prediction of heat transfer on a flat plate subjected to a transversely pulsating jet using artificial neural networks,” Appl. Therm. Eng., vol. 100, pp. 412-420, 2016, doi: 10.1016/j.applthermaleng.2016.01.147.

[14] D. G. Kröger, "Convection heat transfer between a horizontal surface and the natural environment," $R D J$. , vol. 18, no. 3, pp. 49-54, 2002.

[15] J. Mo, A. Choudhry, M. Arjomandi, R. Kelso, and Y. Lee, "Journal of Wind Engineering Effects of wind speed changes on wake instability of a wind turbine in a virtual wind tunnel using large eddy simulation," Jnl. Wind Eng. Ind. Aerodyn., vol. 117, pp. 38-56, 2013, doi: 10.1016/j.jweia.2013.03.007.

[16] L. Guoneng, X. Zhihua, Z. Youqu, G. Wenwen, and D. Cong, "Experimental study on convective heat transfer from a rectangular flat plate by multiple impinging jets in laminar cross flows," Int. J. Therm. Sci., vol. 108, pp. 123-131, 2016, doi: 10.1016/j.jithermalsci.2016.05.006.

[17] A. Horibe, R. Shimoyama, N. Haruki, and A. Sanada, "Experimental study of flow and heat transfer characteristics of natural convection in an enclosure with horizontal parallel heated plates," Int. J. Heat Mass Transf., vol. 55, no. 23, pp. 7072-7078, 2012, doi: 10.1016/j.ijheatmasstransfer.2012.07.021.

[18] U. Madanan and R. J. Goldstein, "Experimental investigation on very-high-Rayleigh-number thermal convection in tilted rectangular enclosures," Int. J. Heat Mass Transf., vol. 139, pp. 121-129, 2019, doi: 10.1016/j.ijheatmasstransfer.2019.05.011.

[19] L. Boukhattem, H. Hamdi, and D. R. Rousse, "Numerical simulation of heat transfers in a room in the presence of a thin horizontal heated plate,” Energy Procedia, vol. 42, pp. 549-556, 2013, doi: 10.1016/j.egypro.2013.11.056.

[20] Q. Liu, Z. Zhao, and K. Fukuda, "Transient heat transfer for forced flow of helium gas along a horizontal plate with different widths," Int. J. Heat Mass Transf., vol. 75, pp. 433-441, 2014, doi: 10.1016/j.ijheatmasstransfer.2014.03.077.

[21] S. M. Elsherbiny, M. A. Teamah, and A. R. Moussa, "Natural convection heat transfer from an isothermal horizontal square cylinder," Alexandria Eng. J., vol. 56, no. 1, pp. 181-187, 2017, doi: 0.1016/j.aej.2016.09.020.

[22] M. Y. Abdollahzadeh Jamalabadi, "Experimental investigation of thermal loading of a horizontal thin plate using infrared camera,” J. King Saud Univ. - Eng. Sci., vol. 26, no. 2, pp. 159-167, 2014, doi: 10.1016/j.jksues.2013.03.002.

[23] G. Ceglia and S. Discetti, "An experimental analysis in horizontal convection with IR thermography," in Proceedings of 11th International Conference on Quantitative InfraRed Thermography, 2012, doi: 10.21611/qirt.2012.324.

[24] P. Rodriguez, "Selection of Materials for Heat Exchangers," in Heb, 1997, vol. 97, pp. 1-72. 
[25] M. J. Silva, P. S. B. Zdanski, and M. Vaz, "Forced convection on grey cast iron plate-fins: Prediction of the heat transfer coefficient," Int. Commun. Heat Mass Transf., vol. 81, pp. 1-7, 2017, doi: 10.1016/j.icheatmasstransfer.2016.11.007.

[26] M. Lee, H. J. Kim, and D.-K. Kim, "Nusselt number correlation for natural convection from vertical cylinders with triangular fins,” Appl. Therm. Eng., vol. 93, pp. 1238-1247, 2016, doi: 10.1016/j.applthermaleng.2015.10.105.

[27] X. Nicolas, E. Chénier, C. Tchekiken, and G. Lauriat, "Revisited analysis of gas convection and heat transfer in micro channels: Influence of viscous stress power at wall on Nusselt number," Int. J. Therm. Sci., vol. 134, pp. 565-584, 2018, doi: 10.1016/j.ijthermalsci.2018.05.049.

[28] M. Vollmer and K. P. Möllmann, Infrared thermal imaging: Fundamentals, research and applications. John Wiley \& Sons, 2017. 